
\title{
PRODUCIF̄O ONLINE

\section{ANÁLISE DOS RISCOS E O PROGRAMA DE PREVENÇÃO DE RISCOS AMBIENTAIS EM UM RESTAURANTE UNIVERSITÁRIO DA REGIÃO NORDESTE}

\section{RISK ANALYSIS AND THE ENVIRONMENTAL RISK PREVENTION PROGRAM IN A UNIVERSITY RESTAURANT IN THE NORTHEAST REGION}

\author{
José Flávio Rique Júnior* E-mail: flaviodinoa@yahoo.com.br \\ Fábio Morais Borges* E-mail: fabiomoraisb@gmail.com \\ Ruan Eduardo Carneiro Lucas* E-mail: ruaneduardo94@gmail.com \\ Caio de Araújo Pereira Gadelha* E-mail: caio gad@hotmail.com \\ Ricardo Moreira* E-mail: ricardomoreira0203@gmail.com \\ *Universidade Federal da Paraíba (UFPB), João Pessoal, PB
}

\begin{abstract}
Resumo: O gerenciamento dos riscos ocupacionais é um fator que deve ser levado atenção por parte dos gestores, pois trazem consequências benéficas tanto para a empresa quanto para os trabalhadores. Para se ter um gerenciamento de riscos ocupacionais efetivo, deve-se cumprir as normas estabelecidas por lei, uma delas é da obrigatoriedade do desenvolvimento e implementação de um Programa de Prevenção de Riscos Ambientais (PPRA). Esse trabalho tem como objetivo analisar os riscos e desenvolver um PPRA para o Restaurante Universitário da Universidade Federal da Paraíba, do campus I em João Pessoa. Para isso vários funcionários foram entrevistados e foi feita a identificação dos riscos ocupacionais encontrados em cada setor do Restaurante. Após a identificação qualitativa, observou-se a necessidade de realizar avaliações quantitativas de determinados riscos encontrados. Posteriormente a todas as informações serem coletadas, teve-se um panorama do plano de gerenciamento e implementou-se o documento base do PPRA do Restaurante Universitário com os elementos fundamentais que o compõe.
\end{abstract}

Palavras-chave: Identificação de Riscos. PPRA. Restaurante Universitário.

Abstract: The management of occupational risks is a factor that must be taken into account by the managers, since they have beneficial consequences both for the company and for the workers. In order to have an effective occupational risk management, one must comply with the norms established by law, one of them is the obligation to develop and implement an Environmental Risk Prevention Program (PPRA). This work aims to analyze the risks and develop a PPRA for the University Restaurant of the Federal University of Paraíba, campus I in João Pessoa. For this, several employees were interviewed and identification of the occupational risks found in each sector of the Restaurant was made. After the qualitative identification, it was observed the need to carry out quantitative assessments of certain risks found. After all the information was collected, an overview of the management plan was carried out and the PPRA base document of the University Restaurant was implemented with the fundamental elements that compose it.

Keywords: Identification of Risks. PPRA. University restaurant.

\section{INTRODUÇÃO}

O Restaurante da Universidade Federal da Paraíba atende cerca de 1.400 
alunos todos os dias, para que estes tenham uma refeição de qualidade todos os componentes do sistema de trabalho do restaurante devem estar funcionando corretamente. Um desses componentes é o sistema de gestão de segurança e saúde no trabalho, o qual garante a segurança dos trabalhadores, aumentando a produtividade e consequentemente a qualidade das refeições.

A segurança do trabalho se caracteriza por um conjunto de medidas que estão presentes e são importantes em qualquer tipo organização produtiva. Nesse sentido, Oliveira (2016) afirma que ela está presente em todo segmento produtivo, identificando, controlando e solucionando situações de acidentes ou causadoras de doenças. Todo esse processo é controlado pelo gerenciamento dos riscos, que segundo Costa (2009) consiste nos processos de identificação, análise, avaliação e resolução dos riscos.

Uma das formas mais utilizadas para facilitar o gerenciamento dos riscos é através do Programa de Prevenção de Riscos Ambientais (PPRA). Para Saad e Giampaoli (2005), esse programa trabalha dentro dos conceitos de gerenciamento e gestão, estando desassociado do simples cumprimento de regras ou procedimentos previamente estabelecidos.

O PPRA tem por objetivo, através da antecipação, do reconhecimento, da avaliação, e do controle dos riscos ambientais existentes ou que possam existir, a preservação da saúde, garantir a integridade dos trabalhadores, e respaldar as empresas normativamente. Entretanto, para o sucesso desse plano é necessária a cooperação da empresa e dos trabalhadores.

Além do respaldo legal que a empresa irá ter ao desenvolver e implementar o PPRA, o documento traz para os gestores a situação atual da empresa em relação aos riscos ocupacionais existentes. Além disso, o documento serve como um direcionamento para os gestores tentarem eliminar os riscos, ou ao menos tentar reduzi-los, com planos e metas direcionados para cada risco.

Sendo assim, o PPRA funciona como uma estratégia e metodologia de ação. Pois, possibilita garantir a implantação de medidas de controle no ambiente de trabalho, para que de maneira eficaz possa garantir a proteção dos trabalhadores. As estratégias e as ações deverão ser determinadas através de reuniões, de planejamento, nas quais deve-se divulgar os dados das avaliações ambientais, e traçar objetivos relacionados a essas avaliações. 
Assim, este trabalho tem o objetivo de analisar os riscos e desenvolver um documento-base do Programa de Prevenção de Riscos Ambientes para o Restaurante Universitário (RU) da Universidade Federal da Paraíba (UFPB)

O Programa de Prevenção de Riscos Ambientais (PPRA) faz parte da etapa do planejamento da gestão de segurança e saúde do trabalho e seus requisitos, onde o conteúdo do mesmo auxilia o sistema a alcançar os seus objetivos.

O PPRA, é obrigatório para todos os estabelecimentos que admitam trabalhadores como empregados segundo a Norma Regulamentadora (NR) 9, aprovada pela Portaria oㅡ 25 em 29 de dezembro de 1994. O PPRA visa a prevenção a saúde e integridade dos trabalhadores, e seus objetivos estão condizentes com os objetivos do sistema de gestão de segurança e saúde do trabalho da organização.

O PPRA é um programa de prevenção de acidentes que é desenvolvido para os ambientes de trabalho de cada organização. Os restaurantes, mais especificamente, os universitários, como toda e qualquer organização, admitem trabalhadores como empregados, portanto são obrigados a desenvolver e implementar um PPRA para o estabelecimento, cumprindo assim as normas estabelecidas por lei, visando a preservação da saúde e integridade física e moral de seus trabalhadores.

Dados retirados da AEAT, o Anuário Estatístico de Acidentes de Trabalho, no período de 2006 a 2015 informa que no Brasil houve 90.002 acidentes de trabalho no setor de restaurantes e outros serviços de alimentação e bebidas, um número relativamente significante dado a importância desse setor no Brasil. Dentro desse cenário, o objetivo desse trabalho é analisar os riscos e desenvolver o documentobase do Programa de Prevenção de Riscos Ambientais para o Restaurante Universitário (RU) da Universidade Federal da Paraíba (UFPB).

Para um entendimento preciso da gestão dos riscos e uma eficiente construção do PPRA, é importante ter um conhecimento e uma base sólida sobre os assuntos que norteiam seu desenvolvimento, assuntos como, segurança no trabalho, definições legais de acidentes de trabalho, definições e os tipos de riscos existentes. Também deve-se ter um conhecimento a respeitos das NR's principalmente daquelas que trabalham juntamente com o PPRA, como a NR 4, NR 5, NR 7, NR 15, dentre outras. 


\section{GERENCIAMENTO DE RISCOS OCUPACIONAIS}

O gerenciamento de riscos ocupacionais é uma atividade que deve ser tratada com atenção e prioridade por parte dos gestores das empresas de qualquer ramo do trabalho. A gestão dos riscos é benéfica tanto para as empresas como principalmente para os trabalhadores. Para as empresas, uma bosta gestão de riscos, em qualquer atividade, evita problemas como acidentes e pagamento de indenizações. Já o trabalhador tem sua integridade física e mental preservada.

Um sistema de gestão de segurança e saúde no trabalho pode ser entendido como um conjunto de políticas, procedimentos e práticas, onde cada uma possui funções específicas, porém ligadas entre si (FERNÁNDEZ-MUÑIZ; MONTESPEÓN; VÁZQUEZ-ORDÁS, 2007). De acordo com Bortolosso (2017) a eficácia do sistema de gestão de segurança e saúde no trabalho irá depender de vários fatores como aspectos gerenciais e culturais.

A norma de Occupational Health and Safety Assesment Series (OHSAS) 18001, direciona as empresas para que elas adotem um sistema de gestão de segurança e saúde do trabalho, e executem de maneira eficaz, estabelecendo metas e objetivos de segurança ocupacional que possam ser cumpridos pela organização. Tal norma permite a empresa o controle dos riscos em saúde e segurança ocupacional (CAMARGO, 2016).

Segundo a OHSAS 18001 (1999, apud CAMARGO, 2016), para se obter um bom sistema de gestão de segurança e saúde do trabalho, as organizações precisam de alguns requisitos que direcionam a empresa. Tais requisitos para o sistema de gestão de segurança e saúde no trabalho são apresentados no Quadro 1 a seguir: 
Quadro 1 - Requisitos da OHSAS 18001

\begin{tabular}{|c|c|}
\hline REQUISITO & SUB-REQUISITO \\
\hline $\begin{array}{c}\text { Política de Segurança e Saúde no } \\
\text { Trabalho }\end{array}$ & \\
\hline Planejamento & $\begin{array}{l}\text { - } \quad \text { Identificação dos perigos e avaliações dos } \\
\text { riscos e determinação de controles; } \\
\text { - } \quad \text { Requisitos legais e outros; } \\
\text { - } \quad \text { Objetivos e Programas. }\end{array}$ \\
\hline Implementação e operação & $\begin{array}{l}\text { - Recursos, funções, responsabilidades, } \\
\text { prestação de contas e autoridades; } \\
\text { - } \quad \text { Competência, treinamento e conscientização; } \\
\text { - } \quad \text { Comunicação, participação e consulta; } \\
\text { - } \quad \text { Cocumentação } \\
\text { - } \quad \text { Preparaçãa documentos } \\
\end{array}$ \\
\hline Verificação & $\begin{array}{l}\text { - Monitoramento de medição do desempenho; } \\
\text { - Avaliação do atendimento a requisitos legais } \\
\text { - Investigação de incidente, não conformidade, } \\
\text { - ação preventiva e corretiva; } \\
\text { - Controle de registros; } \\
\text { - Auditoria interna. }\end{array}$ \\
\hline Análise crítica pela direção & \\
\hline
\end{tabular}

Fonte: Adaptado de Camargo (2016)

\section{SEGURANÇA NO TRABALHO}

Existem diversos elementos que compõem um programa de gestão de segurança no trabalho. De acordo com Oliveira (2003), três elementos sustentam esta gestão. Os aspectos culturais, que levam em consideração as partes interessadas que são os trabalhadores e gestores, por exemplo. Os conteúdos técnicos, que são as ferramentas utilizadas para a identificação e controle dos riscos no trabalho. $E$ os aspectos ligados aos resultados que são os objetivos a serem alcançados. Dito isso, para um bom desenvolvimento de um Programa de Prevenção de Riscos Ambientais (PPRA), todos esses elementos devem estar alinhados ao programa.

A constituição federal diz que os trabalhadores têm direito a proteção de sua saúde, integridade física e moral, dentro de seu ambiente de trabalho. A segurança e saúde do trabalhador são de responsabilidade do empregador e dos profissionais que compõem o ambiente de trabalho (GONÇALVES, 2006).

As ações que englobam a segurança e saúde no trabalho das empresas, são realizadas e coordenadas, pelos Serviços de Segurança e Medicina do Trabalho (SESMT), que atua juntamente com o tripé formado pela Comissão Interna de 
Prevenção de Acidentes (CIPA), pelo Programa de Prevenção de Riscos Ambientais (PPRA) e pelo Programa de Controle Médico de Saúde Ocupacional (PCMSO).

\section{a) Acidente de Trabalho}

Segundo o art. 19 da lei no 8213 define-se acidente de trabalho (AT) como qualquer disfunção que pode ocasionar lesão corporal ou perturbação funcional, que cause a morte, perda ou redução, permanente ou temporária, da capacidade para o trabalho (BRASIL, 1991).

Para a área de prevenção de acidentes, essas definições não são inteiramente adequadas, pois, para a definição que rege a lei de nำ8213, acidente de trabalho é apenas aquele que irá ocasionar algum tipo de lesão.

Uma definição para acidente de trabalho que se adequa bem a área de prevenção é a apresentada por Rodrigues (1995). Segundo ele, acidente de trabalho é todo o evento inesperado e indesejável que interrompe a rotina normal de trabalho, podendo gerar perdas pessoais, materiais ou pelo menos de tempo. Para prevenir e evitar que tais acidentes aconteçam, tantos os trabalhadores como os gestores devem estar atentos ao seu ambiente de trabalho, e aos fatores que o compõem. Um fator bastante importante que existe em todo ambiente de trabalho são os riscos que podem levar aos acidentes. Tais riscos devem ser de conhecimento de todos os envolvidos, tanto trabalhadores como gestores.

\section{b) Riscos}

Para que um acidente de trabalho ocorra, alguma parte do sistema de trabalho como um todo não agiu conforme o planejado ou adequado, ou seja, houve algum tipo de alteração no ambiente de trabalho. Essas alterações podem ser ocasionadas por diversos fatores, deixando os trabalhadores sujeitos a riscos de acidentes de trabalho.

Para Mesquita (1999) riscos no trabalho ou riscos profissionais são situações presentes no local de trabalho, decorrente de fatores que afetam a saúde, segurança e bem-estar do trabalhador, que podem estar relacionados ao processo operacional, classificados como riscos operacionais, ou relacionados ao local de trabalho, que são os chamados riscos ambientais.

De acordo com a NR 9, riscos ambientais, são agentes físicos, químicos e biológicos que dependendo de sua intensidade, concentração e tempo de exposição, 
possam comprometer a saúde e o bem-estar do trabalhador. A NR 15 - Atividades e operações insalubres, determina os limites de exposição do trabalhador a esses agentes.

Riscos ocupacionais são aqueles que podem comprometer a saúde física, mental e social dos trabalhadores, não sendo obrigado a gerar acidentes e doenças, tais riscos são classificados como: risco físicos, químicos, biológicos, ergonômicos e de acidente. (SANTOS; VALOIS, 2007).

Os riscos ocupacionais são definidos de acordo com o Quadro 2 abaixo.

Quadro 2 - Riscos Ocupacionais

\begin{tabular}{|c|c|}
\hline Riscos Físicos & $\begin{array}{l}\text { Os riscos físicos são aqueles provocados por agentes como ruídos, vibrações, } \\
\text { temperaturas extremas, umidade, radiações ionizantes e não ionizantes, podendo } \\
\text { causar um dano a saúde do trabalhador (BARBOSA FILHO, 2011). } \\
\text { Pode-se dizer que os riscos físicos estão presentes em um ambiente de trabalho que, } \\
\text { por exemplo, possau máquinas e equipamentos que geram um barulho bastante } \\
\text { elevado, por características próprias, ou por falta de manutenção. }\end{array}$ \\
\hline Riscos Químicos & $\begin{array}{c}\text { São aqueles provocados por agentes químicos como: poeiras, fumos, névoa, neblinas, } \\
\text { gases, vapores, substâncias compostas e produtos químicos em geral (LAGO, 1997) } \\
\text { Esses agentes químicos possuem a capacidade de alterar a composição química do } \\
\text { ambiente de trabalho, tendo como principais vias de penetração através do aparelho } \\
\text { digestivo, respiratório e pela pele (RODRIGUES, 1995) }\end{array}$ \\
\hline Riscos Biológicos & $\begin{array}{l}\text { Segundo a NR } 9 \text { os riscos biológicos são ocasionados por agentes biológicos, como por } \\
\text { exemplo, bactérias, fungos, bacilos, parasitas, protozoários, vírus, toxinas, entre outros. } \\
\text { A contaminação biológica é feita principalmente através de via cutânea e pericutânea. } \\
\text { Indústrias de alimentos, hospitais, limpeza pública, são exemplos de ambientes em que } \\
\text { este tipo de risco pode ser encontrado facilmente. }\end{array}$ \\
\hline Riscos Ergonômicos & $\begin{array}{c}\text { Agentes que posasm vir a proporcionar desconforto do trabalhador e insegurança podem } \\
\text { ser considerados agentes ergonômicos. Atividades que envolvam esforço físico intenso, } \\
\text { levantamento de peso, posturas inadequadas, situações de estresse, dentre outros, } \\
\text { caracterizam os riscos ergonômicos (LANZA, 2010) }\end{array}$ \\
\hline $\begin{array}{l}\text { Riscos de Acidentes } \\
\text { ou Mecânicos }\end{array}$ & $\begin{array}{c}\text { Qualquer situação que possa pôr em risco a integridade física ou moral. Temos como } \\
\text { exemplos: máquinas sem proteçõa adequada, possibilidades de incêndio, } \\
\text { armazenamento inadequado, arranjos físicos que expõem o trabalhador a essas } \\
\text { situações (BARZOTTO, 2013) }\end{array}$ \\
\hline
\end{tabular}

Fonte: Autoria Própria (2017)

Os gestores têm o dever de manter seus funcionários informados sobre os riscos presentes nos setores de trabalho, por meio de palestras e treinamentos, por exemplo, e também o dever de facilitar o acesso a documentos que os informe. Um recurso utilizado nas empresas para a demonstração dos riscos presentes no ambiente de trabalho é o mapa de risco. 


\section{c) PPRA}

O Programa de Prevenção de Riscos Ambientais (PPRA) é regulamentado pela NR 9, que estabelece a obrigatoriedade da elaboração e implementação do programa, que visa preservar a saúde e integridade dos trabalhadores, mapeando os riscos e dando suporte para outros programas como o PCMSO. Qualquer empregador ou instituição que admita trabalhadores como empregados deverá ter o PPRA na sua empresa. O PPRA é um dos principais documentos exigidos pelas fiscalizações e auditorias.

A NR 9 diz que, o PPRA, visa a preservação da saúde e da integridade do trabalhador, através da antecipação, reconhecimento, avaliação e controle dos riscos existentes ou que possam vir a existir no ambiente de trabalho.

PPRA é a parte integrante de um conjunto de programas e medidas que visam a saúde e a integridade física do trabalhador. O PPRA atua principalmente em conjunto com o PCMSO previsto na NR 7, com a NR 5, a norma regulamentadora da CIPA, e com a NR 15, que fala a respeito das Atividades e Operações Insalubres (BRASIL, 2015e).

Segundo a NR 9, o PPRA deverá conter a seguinte estrutura:

- Planejamento Anual com estabelecimento de metas, prioridades e cronograma;

- Estratégia e metodologia de ação;

- Forma de registro, manutenção e divulgação dos dados;

- Periodicidade e forma de avaliação do desenvolvimento do PPRA.

Ainda de acordo com a NR 9, o PPRA deverá ser apresentado em forma de um documento base, com a estrutura descrita anteriormente. De acordo com Baptista (2016), para que se possa desenvolver um PPRA, deve-se seguir as seguintes etapas:

- Fazer o reconhecimento dos riscos presentes, e se antecipar aos que podem surgir;

- Estabelecer prioridades e metas de avaliação e controle;

- Avaliar os riscos e o grau de exposição dos trabalhadores;

- Implementar medias de controle e avaliar a sua eficácia;

- Monitoramento da exposição dos riscos;

- Registrar os dados. 
Diante do que foi visto, os restaurantes universitários têm a obrigatoriedade de elaborar e implementar o PPRA e o PCMSO para o estabelecimento. O restaurante também terá como dever, coordenar a eleição dos representantes da CIPA.

Além da NR 9, algumas outras normas subsidiam a construção do PPRA. Entre elas estão a NR 6, NR 15, E A NBR 5413.

\section{d) Atividades e operações insalubres}

A NR 15, trata das Atividades e Operações Insalubres em que os limites de tolerância estão previstos em seus anexos. Os anexos da NR 15, prevê limites de tolerância para ruídos, limites de tolerância para exposição ao calor, radiações ionizantes e não ionizantes, trabalhos sob condições hiperbáricas, vibrações, frio, umidade, agentes químicos, limites de tolerância para poeiras minerais e agentes biológicos.

\section{e) Ergonomia}

De acordo com a norma regulamentadora NR 17, cujo o objetivo é definir parâmetros que permitam a adaptação das condições de trabalho as características psicofisiológica dos trabalhadores. As condições de trabalho citadas, diz respeito a aspectos relacionados a levantamento de cargas, transporte e descarga de materiais, aos móveis do ambiente de trabalho e também estão incluso as condições ambientais e a organização do posto de trabalho.

Segundo a NR 17, cabe ao empregador realizar análises ergonômicas do trabalho, com o intuito de abordar as condições de trabalho, avaliando assim as adaptações das condições de trabalho ao trabalhador.

\section{f) lluminância de interiores}

A NBR 5413, trata da iluminação interior de ambientes de trabalho e atividades de comércio, indústria, ensino, esporte dentre outros, e tem por objetivo, estabelecer os níveis de iluminação mínimos. As medidas de iluminação devem acontecer nos campos onde se praticam as atividades. A NBR 5413, conta com o auxílio de tabelas que direcionam de acordo com o tipo de atividade, as pessoas que estão presentes no ambiente de trabalho, levando em consideração o fator da idade do trabalhador. 
Tudo isso para se determinar a faixa mínima necessária de iluminância para cada ambiente e tipo de atividade.

\section{A CONTEXTUALIZAÇÃO DOS RICOS E PPRA EM RESTAURANTES}

Segundo dados da Associação Brasileira de Bares e Restaurantes, a ABRASEL (2015), estima-se que haja um total de um milhão de bares e restaurantes em todo o território nacional, e que tal setor representa $16 \%$ do total das empresas brasileiras. A ABRASEL diz que há uma média de 180 bares restaurantes para cada cidade do Brasil. Tal setor emprega cerca de seis milhões de pessoas. Os restaurantes universitários fazem parte dessas estatísticas.

Os restaurantes universitários constituem o setor de alimentação coletiva, segundo dados da Associação Brasileira das Empresas de Refeições Coletivas ABERC (2017), este setor fornece em torno de 16,9 milhões de refeições por dia e apresenta um faturamento de 17,3 bilhões de reais, referente às refeições coletivas no ano de 2017, mostrando uma importância considerável na economia do país.

De acordo com o SEBRAE (2017), o setor de bares e restaurantes está com uma taxa de expansão anual de 10\%, e gera em torno de 450 mil novos empregos a cada ano.

Com o crescente número de bares e restaurantes no Brasil nos últimos anos, o número de empregos também cresce. Consequentemente mais trabalhadores estão empregados neste setor a cada ano. Com isso é importante estar atento aos possíveis acidentes de trabalho que podem vir a acontecer em bares e restaurantes e também a exposição a riscos que podem gerar sérios agravos a saúde e integridade do trabalhador.

Na Figura 1 tem-se a quantidade de acidentes de trabalho em restaurantes no Brasil, no período de 2006 a 2015, segundo dados da AEAT. 
Figura 1 - Acidentes de Trabalho em Restaurantes, 2006 a 2015

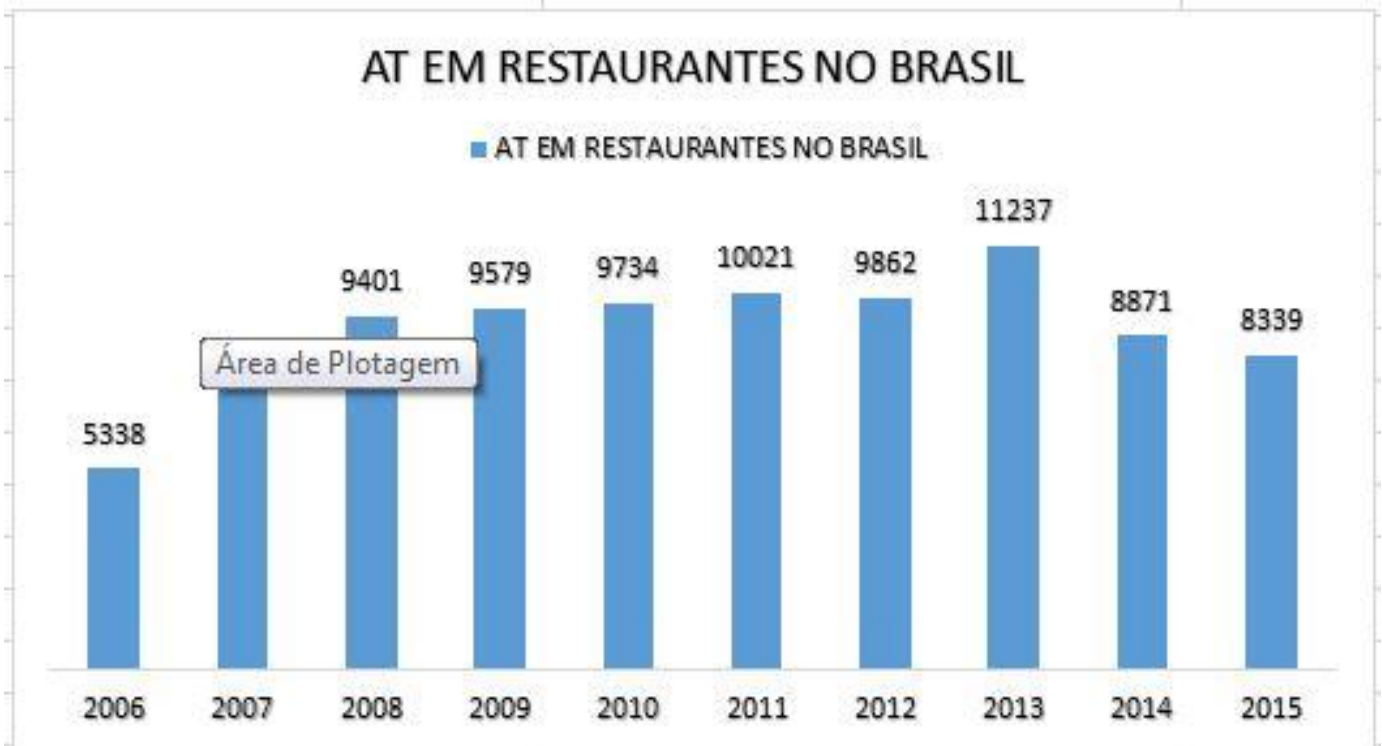

Fonte: Autoria Própria (2017)

Observa-se que de 2006 até o ano de 2013, com exceção do ano de 2012, houve um crescente número de acidentes de trabalho nos restaurantes, e nos anos de 2014 e 2015 houve uma queda no número de acidentes registrados, apesar da crescente expansão do setor.

Filtrando mais essa pesquisa, teve-se acesso aos dados referentes aos acidentes de trabalho no nordeste brasileiro. Foram 7557 acidentes de trabalho em restaurantes dentro desse mesmo período de 2006 a 2015. Os dados estão presentes na Figura 2. Os dados referentes aos acidentes de trabalho em restaurantes no nordeste brasileiro seguem o mesmo padrão dos dados de acidentes no Brasil. 
Figura 2 - Acidentes de Trabalho em Restaurantes no Nordeste, 2006 a 2015

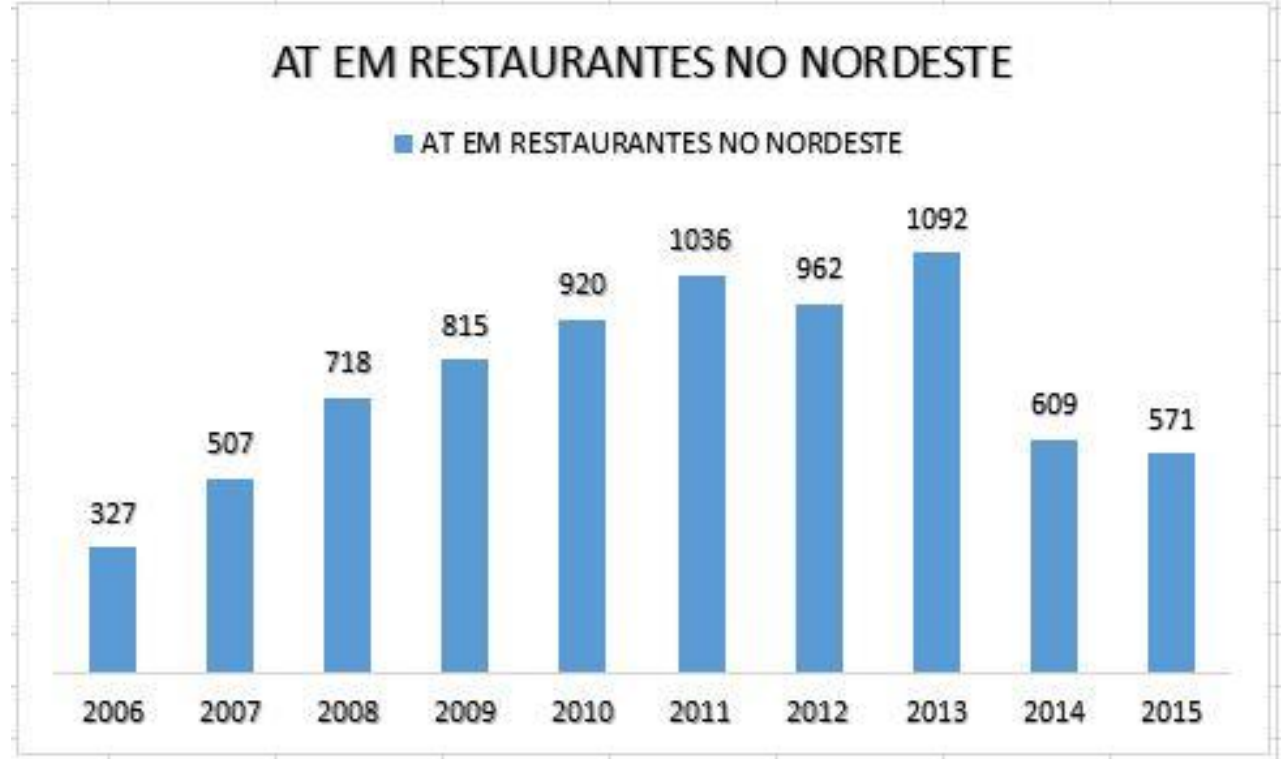

Fonte: Autoria Própria (2017)

Segundo dados do AEAT, na Paraíba, houve um total de 394 acidentes de trabalho, em restaurantes e outros serviços de alimentação, entre 2006 e 2015 . Na figura 3 têm-se os dados de acidentes por ano.

Figura 3 - Acidentes de Trabalho em Restaurantes na Paraíba, 2006 a 2015

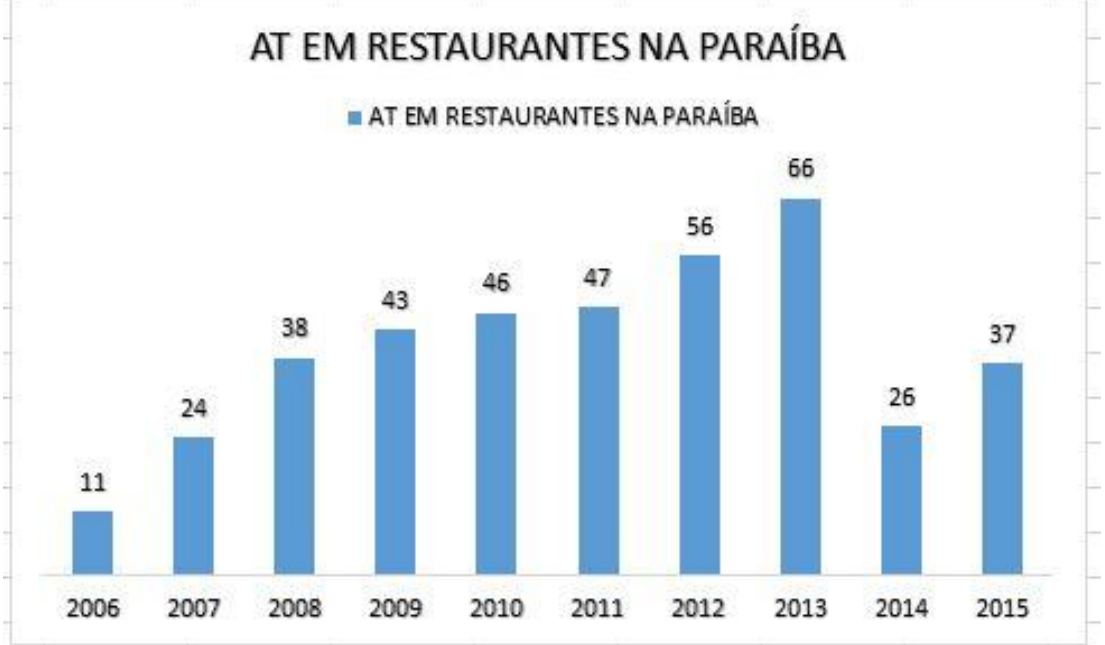

Fonte: Autoria Própria (2017)

Na Paraíba, assim como no Nordeste e no Brasil, de 2006 a 2013, também houve um crescimento no número de acidentes. Em 2014 houve uma redução, porém em 2015 o número de acidentes registrados voltou a crescer.

Analisando os dados anteriores, a Paraíba possui uma representatividade de $5 \%$ em relação aos acidentes de trabalho em bares e restaurantes que ocorrem no Revista Produção Online. Florianópolis, SC, v. 19, n. 2, p. 545-569, 2019. 
nordeste brasileiro. Segundo dados do Instituto Brasileiro de Geografia e Estatística (IBGE) (2017), o nordeste brasileiro atualmente possui 57.254.159 habitantes, já a paraíba possui um total de 4.025.558. A Paraíba representa um percentual de $7 \%$ da população do Nordeste.

\section{METODOLOGIA}

O presente trabalho foi realizado no Restaurante Universitário da Universidade Federal da Paraíba, no campus I em João Pessoa, Paraíba.

A pesquisa se deu por meio de um estudo de caso onde a coleta de foi concebida através de uma série de visitas técnicas ao restaurante. Um estudo de caso se caracteriza como uma pesquisa empírica, que tem seu fundamento em evidências qualitativas e quantitativas, que tem por objetivo, investigar um objeto de estudo inserido no contexto de vida real, assim, o estudo de caso permite que questões do tipo, "por quê?", "o quê?", "como?", sejam respondidas (GANGA, 2012).

Foram realizadas entrevistas com os funcionários para se obter um melhor entendimento de suas atividades diárias. Os funcionários entrevistados foram: o Superintendente do Restaurante Universitário, a nutricionista, cozinheiros, e o auxiliar de serviços gerais. Foram levantadas informações a respeitos dos produtos e quantidades servidas pelo restaurante, como também foram coletadas informações relacionadas aos insumos e aos estoques. Tudo isso com o intuito de mapear todo 0 processo produtivo do restaurante para se ter um bom entendimento do seu funcionamento.

Os riscos foram identificados através das visitas técnicas e a princípio de forma qualitativa. As ponderações dos graus de risco foram feitas através das observações e mediante conhecimento prévio. Assim a ponderação desses riscos foi feita em conjunto com os funcionários, que conhecem a fundo como é realizada a tarefa. Mediante levantamento dos riscos qualitativos, observou-se a necessidade de realizar o levantamento de alguns riscos quantitativamente.

A avaliação quantitativa foi realizada nas variáveis ambientais (Calor, Frio, Ruído, Umidade e lluminação). O equipamento utilizado para a medição da temperatura foi 0 medidor de stress térmico, modelo TGD 400 da marca INSTRUTHERM previamente calibrado. O equipamento foi montado no local a ser 
analisado e se aguardou por 20 minutos até que ele estivesse estabilizado termicamente. O local de medição foi ao lado das panelas industriais onde se têm a maior exposição ao calor pelos funcionários, conforme observação e relato dos próprios trabalhadores.

Utilizou-se para a medição do ruído o audiodosímetro modelo SmartdB da marca CHROMPACK. A calibração foi realizada na hora, seguindo as instruções indicadas no instrumento. O funcionário observado foi o copeiro, pois é o que fica mais exposto ao equipamento mais ruidoso do ambiente, a lavadora de pratos. O instrumento ficou conectado ao trabalhador durante um período de 1 hora e 40 minutos horas. Como o ciclo de atividades que ele realiza se repete, o tempo pode ser projetado para a jornada completa de trabalho, 8 horas. $O$ instrumento permite realizar essa projeção, estabelecendo a dose de ruído para a jornada completa.

Para a iluminação foi utilizado o luximetro digital, modelo LD - 400, da marca INSTRUTHERM. As medições foram realizadas no turno da noite e foram realizadas em todos os postos de trabalho. A avaliação quantitativa dessas variáveis permitiu a comparação com o que está disposto nas normas, possibilitando identificar se as condições estavam adequadas.

\section{RESULTADOS}

A instalação física atual do Restaurante Universitário compreende uma área total de $819,11 \mathrm{~m}^{2}$ localizada na Universidade Federal da Paraíba / Campus I, em João Pessoa - PB. E é dividida em 5 (cinco) grandes áreas, são elas: secretaria, 2 (dois) refeitórios, cozinha e área de carga e descarga. A planta baixa do Restaurante e suas estruturas são apresentadas na Figura 4. 


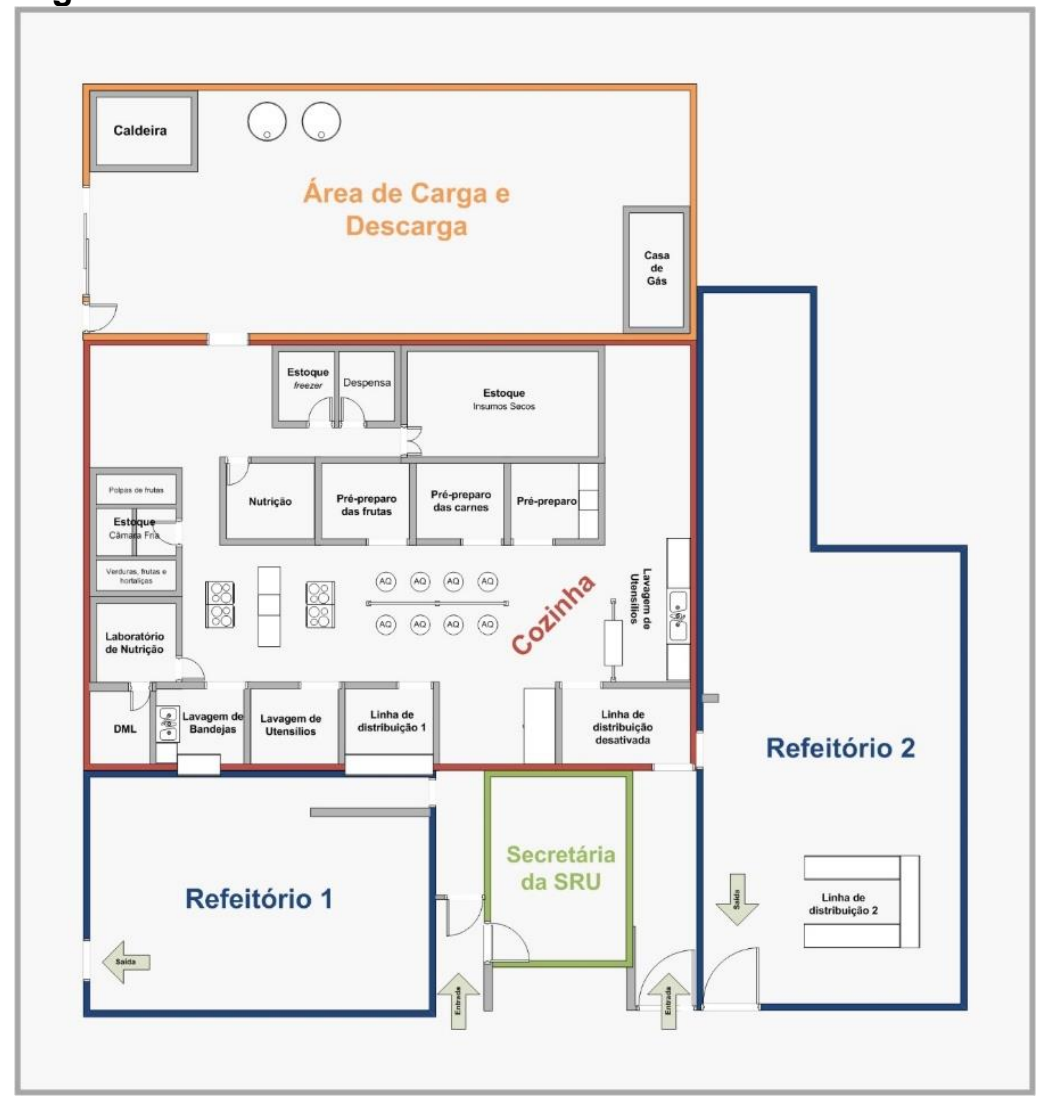

Fonte: Adaptado Superintendência de Restaurantes Universitários (2017)

Atualmente, a prestação de serviço é realizada por uma empresa contratada para o fornecimento de refeições, incluindo o transporte, produção e distribuição. As duas últimas etapas são realizadas nas dependências da Restaurante Universitário $(R U)$. Os produtos gerados são refeições, café da manhã, almoço, jantar e lanche noturno, que são oferecidos gratuitamente para seu corpo discente classificado pela Universidade como de vulnerabilidade social. Ficando a cargo da empresa terceirizada o transporte, produção e distribuição.

Os resultados foram divididos em: Descrição das atividades realizadas; Identificação dos riscos ambientais; Avaliação das variáveis ambientais; e Recomendações gerais e prazo para resolução dos riscos.

\subsection{Descrição das atividades realizadas}

O RU conta com um quadro de 29 funcionários, onde suas funções e atividades estão descritas no Quadro 3. Assume-se a existência de dois açougueiros; dois auxiliares de serviços gerais; seis auxiliares de cozinha; um cozinheiro chefe; dois 
cozinheiros; dez copeiras; uma saladeira; duas nutricionistas; um operador de caldeira e dois motoristas. Mediante descrição das atividades visualizou-se que algumas delas que apresentavam um maior risco a saúde dos profissionais. Dentre estas, exemplificam-se as tarefas de Açougueiro e Operador de Caldeira.

Quadro 3 - Quadro de Funcionários

\begin{tabular}{|c|c|c|}
\hline Setor & Função & Descrição das Atividades \\
\hline Cozinha & $\begin{array}{l}\text { Açougueiro } \\
(02)\end{array}$ & $\begin{array}{l}\text { - Participa do recebimento da carne; } \\
\text { - Retalha as peças conforme a necessidade, fazendo } \\
\text { o pré-preparo; } \\
\text { - Desempenhar outras atividades similares e afins. }\end{array}$ \\
\hline Cozinha & $\begin{array}{c}\text { Auxiliar de Serviços Gerais } \\
(02)\end{array}$ & $\begin{array}{l}\text { - Responsável por manter a limpeza e a higiene de } \\
\text { todo o Restaurante Universitário; } \\
\text { - Efetuar a limpeza de utensílios, mantendo-os em } \\
\text { condições de uso; } \\
\text { - Executar Atividades de Copa; } \\
\text { - Reabastecer os banheiros com papel higiênico, } \\
\text { toalhas e sabonetes; } \\
\text { - Desempenhar outras atividades similares e afins. }\end{array}$ \\
\hline Cozinha & Auxiliar de Cozinha (06) & $\begin{array}{l}\text { - Responsável pelo pré-preparo, higienização e } \\
\text { pequenas produções de alimentos de vários setores } \\
\text { da cozinha; } \\
\text { - Lavar, descascar, cortar e ralar os alimentos. }\end{array}$ \\
\hline Cozinha & Cozinheiro Chefe (01) & $\begin{array}{l}\text { - Responsável pela seleção dos ingredientes; } \\
\text { - } \quad \text { Coordenar atividades relacionadas ao preparo das } \\
\text { refeições; } \\
\text { - } \\
\text { - } \\
\text { Responpanhar e cozinhar os alimentos; } \\
\text { cozinha; }\end{array}$ \\
\hline Cozinha & Cozinheiro (02) & $\begin{array}{l}\text { - } \begin{array}{l}\text { Coordenar as atividades relacionadas ao preparo } \\
\text { das refeições. }\end{array} \\
\text { - Preparar as refeições sob a supervisão de um } \\
\text { nutricionista, realizando a tarefa de acordo com os } \\
\text { métodos de cozimento e mantendo o padrão de } \\
\text { qualidade dos alimentos; } \\
\text { - Manter higienizado as louças e utensílios; } \\
\text { - Manter os alimentos estocados em conservados; } \\
\text { - Desempenhar outras atividades similares e afins. }\end{array}$ \\
\hline Cozinha & Copeira (10) & $\begin{array}{l}\text { - Manusear e preparar os alimentos; } \\
\text { - Servir as refeições; } \\
\text { - Manter as bandejas organizadas; } \\
\text { - Recolher utensílios e equipamentos utilizados, } \\
\text { - } \text { mantendo a higiene e a conservação; } \\
\text { - } \quad \text { Desempentar a limpeza da cozinha; } \\
\end{array}$ \\
\hline Cozinha & Saladeira (01) & $\begin{array}{l}\text { - Responsável pelo corte e preparo das saladas, } \\
\text { legumes e verduras; } \\
\text { - Zelar pela limpeza e conservação dos alimentos. }\end{array}$ \\
\hline
\end{tabular}


Quadro 3 - Quadro de Funcionários

\begin{tabular}{|c|c|c|}
\hline Setor & Função & Descrição das Atividades \\
\hline Cozinha & Nutricionista (02) & $\begin{array}{l}\text { - } \quad \text { Supervisionar a higiene dos alimentos; } \\
\text { - Gerir as compras e reposição de estoques dos } \\
\text { - } \quad \text { alimentos; } \\
\text { - } \quad \text { Gerir os funcionários do restaurante universitários. } \\
\text { - Manter o padrão de qualidade. }\end{array}$ \\
\hline $\begin{array}{c}\text { Área de Carga e } \\
\text { Descarga }\end{array}$ & Operador de Caldeira (01) & $\begin{array}{l}\text { - Manter a caldeira em estado funcional; } \\
\text { - Realizar manutenções periódicas para garantir o } \\
\text { correto funcionamento. }\end{array}$ \\
\hline $\begin{array}{c}\text { Área de Carga e } \\
\text { Descarga }\end{array}$ & Motorista (02) & $\begin{array}{l}\text { - Responsável pelo transporte de funcionários, de } \\
\text { cargas e documentos relacionados ao Restaurante } \\
\text { Universitário; } \\
\text { - Realizar manutenções básicas do veículo. }\end{array}$ \\
\hline
\end{tabular}

Fonte: Autoria Própria (2017)

\subsection{Identificação dos riscos ambientais}

$\mathrm{O}$ quadro 4 indica os riscos existentes $\mathrm{RU}$; seu agente causador; sua fonte geradora; seu meio de propagação; o número de profissionais expostos e que tipo de exposição estão submetidos.

Os riscos físicos encontrados foram Ruído, Calor, Umidade e Frio. Com relação ao ruído ele foi identificado na Cozinha e nos Refeitórios 1 e 2 . O calor por sua vez foi identificado Cozinha; nos Refeitórios 1 e 2; e na área de carga/descarga. A umidade estava presente Cozinha, enquanto que o frio foi identificado Cozinha/Câmara Fria. O risco químico foi encontrado na Cozinha onde estavam expostos 23 trabalhadores. Já os riscos biológicos foram identificados no chão e no ar da Cozinha e nos Refeitórios 1 e 2 .

Com relação aos riscos ergonômicos observa-se que eles estavam presentes através do Esforço Físico de 26 funcionários; do maior nível de exigência no trabalho noturno de outros 9 trabalhadores; e de posturas inadequadas de outros 29 trabalhadores. Com relação aos riscos de acidente, eles foram identificados através da possibilidade cortes; escoriações e queimaduras.

Com relação ao tipo de exposição, assume-se que os funcionários estavam na maior parte do tempo submetidos de maneira continua aos riscos de acidente, físicos, químicos e biológicos. Com relação aos riscos ergonômicos o tipo de exposição era eventual. 
Quadro 4 - Identificação dos Riscos

\begin{tabular}{|c|c|c|c|c|c|c|}
\hline Setor/Local & Risco & Agente & Causa/Fonte Geradora & $\begin{array}{c}\text { Meio de } \\
\text { Propagação }\end{array}$ & \begin{tabular}{|c|} 
Tipo de \\
Exposição
\end{tabular} & $\begin{array}{c}\begin{array}{c}\text { № de Trabalhadores } \\
\text { Expostos }\end{array} \\
\end{array}$ \\
\hline $\begin{array}{c}\text { Cozinha/Cozimento de } \\
\text { Refeições e Lavagem de } \\
\text { utensilios e bandejas }\end{array}$ & Físico & Ruído & $\begin{array}{l}\text { Conjunto de todos os } \\
\text { equipamentos e pessoas }\end{array}$ & Ar & Contínuo & 23 \\
\hline $\begin{array}{c}\text { Cozinha/Cozimento de } \\
\text { Refeições e Lavagem de } \\
\text { utensiilios e bandejas } \\
\end{array}$ & Físico & Calor & $\begin{array}{l}\text { Fogões/Fornos/Panelas } \\
\text { Industriais }\end{array}$ & Ar & Contínuo & 23 \\
\hline $\begin{array}{c}\text { Cozinha/Cozimento de } \\
\text { Refeições e Lavagem de } \\
\text { utensílios }\end{array}$ & Físico & Umidade & $\begin{array}{l}\text { Água por todo o piso e } \\
\text { vapor }\end{array}$ & Chão e Ar & Contínuo & 26 \\
\hline Cozinha/Câmara Fria & Físico & Frio & Câmara fria & $\mathrm{Ar}$ & Contínuo & 13 \\
\hline $\begin{array}{c}\text { Cozinha/Cozimento de } \\
\text { Refeições e Lavagem de } \\
\text { utensillios }\end{array}$ & Químico & Vapores & Fervura das panelas & Ar & Contínuo & 23 \\
\hline $\begin{array}{c}\text { Cozinha/Cozimento de } \\
\text { Refeições e Lavagem de } \\
\text { utensílios }\end{array}$ & Biológico & Fungos e Bactérias & Umidade & Chão e Ar & Contínuo & 23 \\
\hline Cozinha & Ergonômico & Esforço Físico & $\begin{array}{c}\text { Equipamentos e ambientes } \\
\text { de trabalho inadequados }\end{array}$ & $\begin{array}{c}\text { Contato direto } \\
\text { com a fonte }\end{array}$ & Eventual & 26 \\
\hline Cozinha & Ergonômico & Trabalho Noturno & $\begin{array}{c}\text { Equipamentos e ambientes } \\
\text { de trabalho inadequados }\end{array}$ & $\begin{array}{c}\text { Contato direto } \\
\text { com a fonte }\end{array}$ & Eventual & 9 \\
\hline Área Predial & Ergonômico & Posturas inadequadas & $\begin{array}{c}\text { Equipamentos e ambientes } \\
\text { de trabalho inadequados }\end{array}$ & $\begin{array}{c}\text { Contato direto } \\
\text { com a fonte }\end{array}$ & Eventual & 29 \\
\hline $\begin{array}{c}\text { Cozinha/Cozimento de } \\
\text { refeições }\end{array}$ & Acidente & Queimaduras & $\begin{array}{c}\text { Contato com } \\
\text { equipamentos aquecidos }\end{array}$ & Contato Físico & Contínuo & 9 \\
\hline Cozinha & Acidente & Cortes e Escoriações & $\begin{array}{l}\text { Equipamentos sem } \\
\text { proteção }\end{array}$ & Contato Físico & Contínuo & 26 \\
\hline Cozinha & Acidentes & Escoriações & $\begin{array}{c}\text { Insumos e utensílios } \\
\text { empilhados de forma } \\
\text { inadequada }\end{array}$ & Contato Físico & Contínuo & 26 \\
\hline Cozinha & Acidentes & Cortes e Escoriações & Piso escorregadio & Contato Físico & Contínuo & 26 \\
\hline $\begin{array}{l}\text { Cozinha/Preparo de } \\
\text { Carnes e Saladas }\end{array}$ & Acidentes & Cortes e Escoriações & $\begin{array}{c}\text { Manuseio de ferramentas } \\
\text { de trabalho como facas e } \\
\text { garfos }\end{array}$ & Contato Físico & Contínuo & 9 \\
\hline Refeitório 1 e 2 & Físico & Calor & Estrutura física predial & $\mathrm{Ar}$ & Contínuo & 8 \\
\hline Refeitório 1 e 2 & Físico & Ruído & $\begin{array}{l}\text { Todos os componentes } \\
\text { presentes no ambiente }\end{array}$ & Ar & Contínuo & 8 \\
\hline Refeitório 1 e 2 & Biológico & $\begin{array}{c}\text { Proliferação de } \\
\text { bactérias e fungos }\end{array}$ & $\begin{array}{l}\text { Acumulo de sujeira em } \\
\text { determinados pontos }\end{array}$ & Chão e Ar & Eventual & 8 \\
\hline Área de Carga e Descarga & Físico & Calor & Caldeira & Ar & Eventual & 3 \\
\hline Área de Carga e Descarga & Acidentes & Cortes e Escoriações & Transporte de cargas & Contato Físico & Eventual & 4 \\
\hline
\end{tabular}

Fonte - Elaboração Própria (2017)

Para melhor visualização dos riscos e entendimento da sua localização no ambiente de trabalhado desenvolveu-se o mapa de risco presente na figura 5 abaixo. Como era esperado e visualiza-se na figura, a cozinha era o ambiente que necessitava de um maior cuidado e atenção. 
Figura 5 - Mapa de Riscos

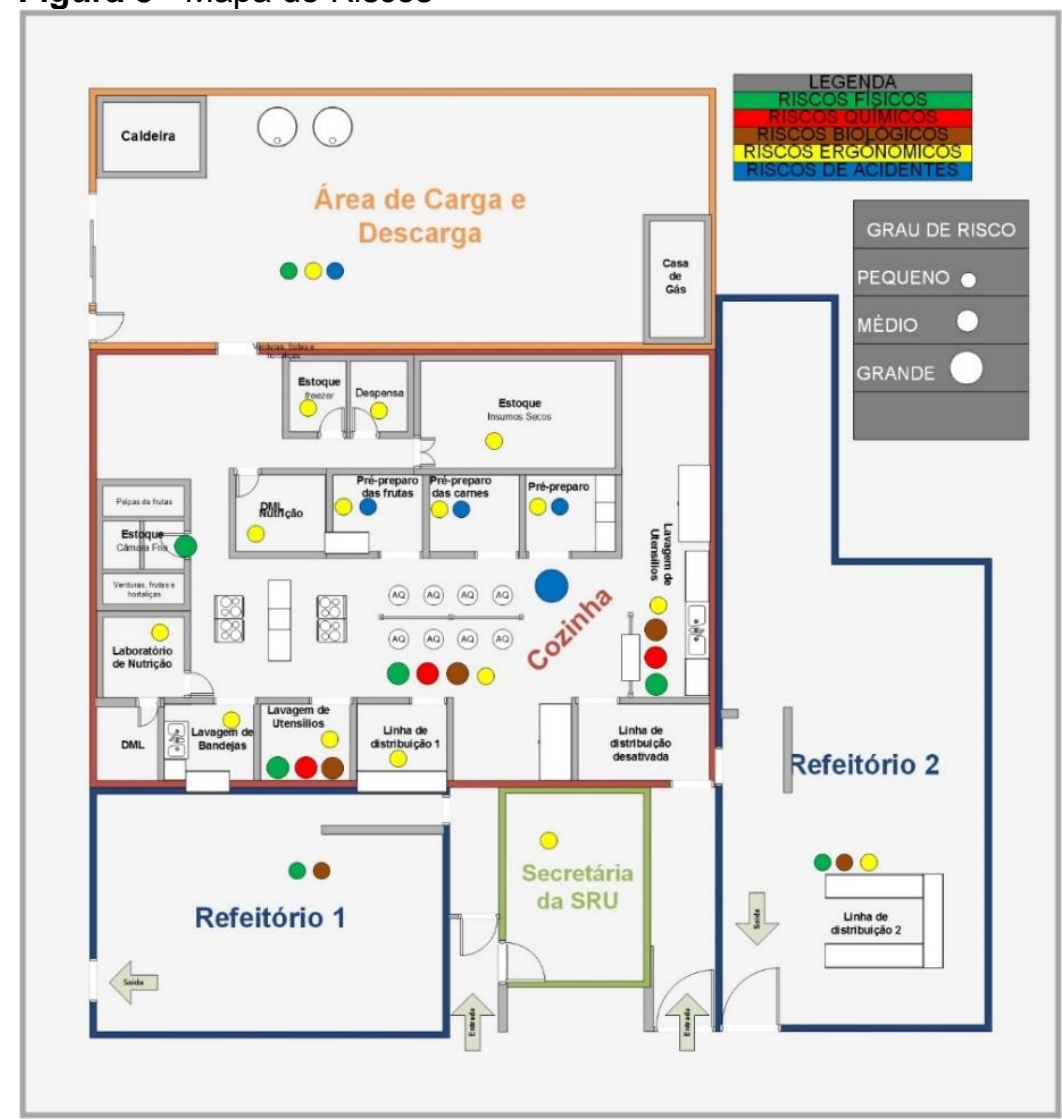

Fonte: Autoria Própria (2017)

\subsection{Avaliação das variáveis ambientais}

Com relação as variáveis térmicas o índice utilizado foi o IBUTG. O Quadro 5 abaixo indica os valores encontrados, e que quando analisados em conjunto do tipo de atividade que estava sendo realizada, o regime de trabalho ideal previsto seria de 45 minutos de trabalho e 15 minutos de descanso no ponto 2, e de 30 minutos de trabalho e 30 de descanso no ponto 1, para um trabalho contínuo.

Quadro 5 - Medições de Temperatura

\begin{tabular}{|c|c|}
\hline FONTE GERADORA & IBUTG \\
\hline Cozinha: Ponto 1 & 28,3 \\
\hline Cozinha: Ponto 2 & 28 \\
\hline
\end{tabular}

Fonte: Autoria Própria (2017)

Com relação aos níveis de ruído o audiodosimetro gera um relatório com as informações da medição, essas informações estão ilustradas na Figura 18 abaixo. $O$ audiodosímetro trabalha com valores de tolerância referentes a NR 15, portanto a dose para 8 horas informada na Tabela 1, diz que o ruído nos locais de trabalho 
medidos estão 303,1\% a mais do permitido, ou seja, 3 vezes o valor de limite de tolerância máximo para uma jornada de trabalho de 8 diárias.

Tabela 1 - Resultados Dosímetro

\begin{tabular}{lrlr|}
\hline LAVG: & $93,0 \mathrm{~dB}(\mathrm{~A})$ & LMAX: & $114,4 \mathrm{~dB}(\mathrm{~A})$ \\
LEQ: & $94,8 \mathrm{~dB}(\mathrm{~A})$ & LMAX Time: (hh:mm) & $12: 48$ \\
TWA: & $81,7 \mathrm{~dB}(\mathrm{~A})$ & LPico:>115 dB & $135,0 \mathrm{~dB}(\mathrm{~A})$ \\
NEN: & $93,0 \mathrm{~dB}(\mathrm{~A})$ & LPico Time: (hh:mm) & $11: 48$ \\
DOSE: & $64,0 \%$ & LMin: & $73,6 \mathrm{~dB}(\mathrm{~A})$ \\
DOSE & $303,1 \%$ & DOSEpos:00:00 & $303,1 \%$ \\
\hline
\end{tabular}

Fonte: Relatório de dosimetria de ruído

Com relação a iluminação, a Tabela 2 mostra os valores medidos no RU e os mínimos exigidos previamente vistos. Observa-se que em todos os setores, exceto o de nutrição, estão com os níveis de iluminamento abaixo dos exigidos.

Tabela 2 - Níveis de lluminamento RU

\begin{tabular}{ccc}
$\begin{array}{c}\text { POSTO DE } \\
\text { OBSERVAÇÃO }\end{array}$ & $\begin{array}{c}\text { NÍVEIS DE } \\
\text { ILUMINAMENTO } \\
\text { OBTIDOS }\end{array}$ & $\begin{array}{c}\text { NÍVEIS MÍNIMOS } \\
\text { EXIGIDOS }\end{array}$ \\
\hline Estoque Freezer & 38,4 & 200 \\
Despensa & 170 & 200 \\
Estoque (INSUMOS SECOS) & 143 & 200 \\
Polpas de Frutas & 2 & 200 \\
Câmara Fria & 13,5 & 200 \\
Verduras Frutas e Hortaliças & 3,8 & 200 \\
Nutrição & 225 & 200 \\
Pré-Preparo de Frutas & 203 & 500 \\
Pré-Preparo das Carnes & 131 & 500 \\
Pré-Preparo & 127 & 500 \\
Laboratório de Nutrição & 120 & 200 \\
Lavagem de Bandejas & 178,4 & 500 \\
Lavagem de Utensílios & 85,6 & 500 \\
Linha de Distribuição 1 & 85,7 & 200 \\
Cozinha/Fornos & 28,3 & 500 \\
Cozinha/Panelas Industriais & 72,3 & 500 \\
\hline
\end{tabular}

Fonte: Autoria Própria (2017)

\subsection{Medidas de controle}

O quadro 6 abaixo indica as soluções proposta e o responsável para cada um dos riscos listados anteriormente. Destaca-se que as soluções tinham um tempo médio de dois meses para resolução, e o tempo final para que todas fossem solucionadas de três meses. Considera-se ainda que a maioria dos riscos não seriam resolvidos de maneira interna, ou seja, é necessário a contratação de empresas terceirizadas para resolução das problemáticas. 
Quadro 6 - Medidas de Controle

\begin{tabular}{|c|c|c|c|c|}
\hline SETOR/LOCAL & RISCO & AGENTE & PROPOSTA & RESPONSÁVEL \\
\hline $\begin{array}{l}\text { Cozinha/Cozimento } \\
\text { de Refeições e } \\
\text { Lavagem de } \\
\text { utensílios/ Lavagem } \\
\text { de Bandejas }\end{array}$ & Físico & Ruído & $\begin{array}{c}\text { Deve-se de acordo } \\
\text { com avaliação } \\
\text { quantitativa, promover } \\
\text { uma medida } \\
\text { organizacional, como o } \\
\text { rodízio dos copeiros a } \\
\text { cada duas horas }\end{array}$ & $\begin{array}{l}\text { Empresa } \\
\text { Contratada }\end{array}$ \\
\hline $\begin{array}{c}\text { Cozinha/Cozimento } \\
\text { de } \\
\text { Refeições/Lavagem } \\
\text { de utensílios/ } \\
\text { Lavagem de } \\
\text { Bandejas }\end{array}$ & Físico & Calor & $\begin{array}{l}\text { Instalação de Novos } \\
\text { Exaustores, e } \\
\text { mudança no tempo de } \\
\text { trabalho dos } \\
\text { operadores das } \\
\text { panelas industriais, } \\
\text { com jornadas de } 45 \\
\text { minutos de trabalho e } \\
15 \text { minutos de } \\
\text { descanso, e } 30 \\
\text { minutos de trabalho e } \\
30 \text { minutos de } \\
\text { descanso }\end{array}$ & $\begin{array}{l}\text { Empresa } \\
\text { Contratada }\end{array}$ \\
\hline $\begin{array}{l}\text { Cozinha/Cozimento } \\
\text { de refeições e } \\
\text { lavagem de utensílios }\end{array}$ & Físico & Umidade & $\begin{array}{l}\text { Reavaliar com os } \\
\text { técnicos responsáveis } \\
\text { os sistemas de } \\
\text { drenagem }\end{array}$ & $\begin{array}{l}\text { Gestão do } \\
\text { Restaurante } \\
\text { Universitário }\end{array}$ \\
\hline Cozinha/Câmara Fria & Físico & Frio & $\begin{array}{c}\text { Fornecimento de EPI's } \\
\text { adequados para } \\
\text { trabalhos no frio. Ex: } \\
\text { Luvas Térmicas e } \\
\text { japonas } \\
\end{array}$ & $\begin{array}{l}\text { Empresa } \\
\text { Contratada }\end{array}$ \\
\hline $\begin{array}{l}\text { Cozinha/Cozi mento } \\
\text { de Refeições e } \\
\text { Lavagem de } \\
\text { utensílios }\end{array}$ & Químico & Vapores & $\begin{array}{l}\text { Aumentar a ventilação } \\
\text { e exaustão do local }\end{array}$ & $\begin{array}{l}\text { Empresa } \\
\text { Contratada }\end{array}$ \\
\hline $\begin{array}{l}\text { Cozinha/Cozi mento } \\
\text { de Refeições e } \\
\text { Lavagem de } \\
\text { utensílios }\end{array}$ & Biológico & $\begin{array}{l}\text { Possível } \\
\text { proliferação } \\
\text { de fungos e } \\
\text { bactérias }\end{array}$ & $\begin{array}{l}\text { Higiene Rigorosa no } \\
\text { local de trabalho }\end{array}$ & $\begin{array}{l}\text { Auxiliares de } \\
\text { Serviços Gerais }\end{array}$ \\
\hline Cozinha & Ergonômico & Esforço Físico & $\begin{array}{l}\text { Pausas pré- } \\
\text { estabelecidas }\end{array}$ & $\begin{array}{l}\text { Empresa } \\
\text { Contratada }\end{array}$ \\
\hline Cozinha & Ergonômico & $\begin{array}{l}\text { Trabalho } \\
\text { Noturno }\end{array}$ & $\begin{array}{c}\text { Fornecer Nível de } \\
\text { Iluminação adequado } \\
\text { no ambiente, pausas } \\
\text { programadas durante } \\
\text { a jornada } \\
\end{array}$ & $\begin{array}{l}\text { Empresa } \\
\text { Contratada }\end{array}$ \\
\hline Área Predial & Ergonômico & $\begin{array}{l}\text { Posturas } \\
\text { inadequadas }\end{array}$ & $\begin{array}{c}\text { Providenciar uma } \\
\text { Análise Ergonômica do } \\
\text { Trabalho }\end{array}$ & $\begin{array}{l}\text { Empresa } \\
\text { Contratada }\end{array}$ \\
\hline $\begin{array}{l}\text { Cozinha/Cozimento } \\
\text { de refeições }\end{array}$ & Acidente & Queimaduras & $\begin{array}{c}\text { Fornecer luvas de } \\
\text { proteção }\end{array}$ & $\begin{array}{l}\text { Empresa } \\
\text { Contratada }\end{array}$ \\
\hline Cozinha & Acidente & $\begin{array}{l}\text { Cortes e } \\
\text { Escoriações }\end{array}$ & $\begin{array}{l}\text { Fornecer proteções } \\
\text { para os equipamentos } \\
\text { e luvas de proteção }\end{array}$ & $\begin{array}{l}\text { Empresa } \\
\text { Contratada }\end{array}$ \\
\hline
\end{tabular}


Quadro 6 - Medidas de Controle

\begin{tabular}{|c|c|c|c|c|}
\hline SETOR/LOCAL & RISCO & AGENTE & PROPOSTA & RESPONSÁVEL \\
\hline Cozinha & Acidentes & Escoriações & $\begin{array}{c}\text { Armazenar de maneira } \\
\text { adequada os insumos e } \\
\text { utensílios }\end{array}$ & $\begin{array}{c}\text { Auxiliar de } \\
\text { serviços gerais, } \\
\text { Cozinheiros, } \\
\text { Copeiras, } \\
\text { Nutricionista }\end{array}$ \\
\hline Cozinha & Acidentes & $\begin{array}{c}\text { Cortes e } \\
\text { Escoriações }\end{array}$ & $\begin{array}{l}\text { Fornecimento de } \\
\text { calçados adequados e } \\
\text { antiderrapantes }\end{array}$ & $\begin{array}{l}\text { Empresa } \\
\text { Contratada }\end{array}$ \\
\hline $\begin{array}{c}\text { Cozinha/Preparo de } \\
\text { carnes e Preparo de } \\
\text { Saladas }\end{array}$ & Acidentes & $\begin{array}{l}\text { Cortes e } \\
\text { escoriações }\end{array}$ & $\begin{array}{c}\text { Treinamentos para o } \\
\text { manuseio correto de } \\
\text { equipamentos perfuro- } \\
\text { cortantes }\end{array}$ & $\begin{array}{l}\text { Empresa } \\
\text { Contratada }\end{array}$ \\
\hline Refeitório 1 e 2 & Físico & Calor & $\begin{array}{c}\text { Providenciar sistema de } \\
\text { ventilação }\end{array}$ & $\begin{array}{l}\text { Empresa } \\
\text { Contratada }\end{array}$ \\
\hline Refeitório 1 e 2 & Físico & Ruído & $\begin{array}{l}\text { Fornecer protetores } \\
\text { auriculares aos } \\
\text { funcionários }\end{array}$ & $\begin{array}{l}\text { Empresa } \\
\text { Contratada }\end{array}$ \\
\hline Refeitório 1 e 2 & Biológico & $\begin{array}{l}\text { Proliferação de } \\
\text { bactérias e } \\
\text { fungos }\end{array}$ & $\begin{array}{l}\text { Higiene Rigorosa no } \\
\text { local de trabalho }\end{array}$ & $\begin{array}{c}\text { Auxiliares de } \\
\text { Serviços Gerais }\end{array}$ \\
\hline $\begin{array}{c}\text { Área de Carga e } \\
\text { Descarga }\end{array}$ & Físico & Calor & $\begin{array}{c}\text { Aumentar a ventilação e } \\
\text { exaustão do local }\end{array}$ & $\begin{array}{l}\text { Empresa } \\
\text { Contratada }\end{array}$ \\
\hline $\begin{array}{c}\text { Área de Carga e } \\
\text { Descarga }\end{array}$ & Acidentes & $\begin{array}{c}\text { Cortes e } \\
\text { Escoriações }\end{array}$ & $\begin{array}{l}\text { Treinamento adequado } \\
\text { para o manuseio de } \\
\text { cargas }\end{array}$ & $\begin{array}{l}\text { Empresa } \\
\text { Contratada }\end{array}$ \\
\hline
\end{tabular}

Fonte: Autoria Própria (2017)

\section{CONCLUSÕES}

O objetivo desse trabalho foi analisar os riscos e desenvolver o documentobase do Programa de Prevenção de Riscos Ambientais para o Restaurante Universitário (RU) da Universidade Federal da Paraíba (UFPB).

Com relação aos riscos identificados assume-se a existência de riscos físicos em função do Ruído, Calor, Umidade e Frio. Existiram riscos biológicos (Fungos e bactérias); ergonômicos em função de posturas inadequadas; e riscos de acidentes em função de objetos que poderiam causar cortes, escoriações e queimaduras. Por outro lado, destaca-se a inexistência de riscos químicos.

O mapa de risco possibilitou identificar os espaços que necessitavam de maior atenção. A cozinha foi o espaço que apresentou os riscos em maior número e com maior grau de periculosidade. A área de Carga/Descarga apresentou riscos médio de acidentes; riscos físicos e ergonômicos. O Refeitório 2 por sua vez apresentou riscos biológicos, físicos e de acidentes em um grau médio. Por fim, o Refeitório 1 apresentou 
riscos físicos e biológicos de nível médio; e a Secretária apresentou o risco ergonômico.

Com relação as variáveis ambientais, assume-se que o ruído nos locais aferidos estava 3 vezes acima do valor limite máximo para uma jornada de trabalho de 8 diárias. Com relação a iluminação do ambiente, assume-se que odos os setores, exceto o de nutrição, estavam com os níveis de iluminamento abaixo dos exigidos.

$\mathrm{Na}$ opinião dos alunos o ambiente apresentava todos os atributos para evitar a ocorrência de acidentes e o surgimento de doenças no longo prazo. Entretanto, os resultados encontrados mediante avaliação caminharam em um sentido oposto, onde indicaram a existência de pontos deficientes e alertaram para que se tenha uma maior atenção com relação as condições desse restaurante.

Sendo assim, o desenvolvimento do PPRA possibilitou o entendimento da importância do documento na gestão dos riscos das empresas e principalmente de um restaurante. Além disso, reconheceu-se que não se trata apenas de um documento, e sim de um programa que deve ser acompanhado durante toda sua vigência, cumprindo seus objetivos e metas, e sempre que necessário ser reavaliado.

\section{REFERÊNCIAS}

ABERC (SÃO PAULO). Mercado real. 2017. Disponível em:

http://www.aberc.com.br/mercadoreal.asp?IDMenu=21. Acesso em: 25 out. 2017.

ABRASEL. Bares e Restaurantes são a alavanca do Brasil empreendedor. Disponível em: http://www.abrasel.com.br/noticias/3164-07012015-bares-e-restaurantes-sao-aalavanca-do-brasil-empreendedor.html. Acesso em: 13 out. 2017

AEAT. Base de dados históricos de acidentes do trabalho. Disponível em: http://www3.dataprev.gov.br/AEAT/greg/reg05/reg05.PHP. Acesso em: 14 out. 2017.

ASSOCIAÇÃO BRASILEIRA DE NORMAS TÉCNICAS. NBR 5413: iluminância de interiores. ABNT, 1992.

BAPTISTA, Thiago Takaoka Alves; PIZO, Carlos Antônio. Riscos ocupacionais: estudo de caso de uma empresa fabricante de colchões e seu ppra. Trabalhos de Conclusão de Curso do DEP, 2016.

BARBOSA FILHO, A. N. Segurança do trabalho e gestão ambiental. 4.ed. São Paulo: Atlas, 2011;

BARZOTTO, Paula Cristina. Estudo de riscos ambientais na indústria frigorífica: processos abate de frango, 2013. Monografia (Especialização em Engenharia de Segurança do Trabalho) - CEEST. Curitiba, 2013. 
BRASIL. Lei $\mathbf{n} \mathbf{0} \mathbf{8 . 2 1 3 / 9 1}$. Planalto. Disponível em:

http://www.planalto.gov.br/ccivil_03/leis/L8213cons.htm. Acesso em: 19 out. 2017.

BRASIL(e). Ministério do Trabalho e Emprego. Norma Regulamentadora 4: Serviços Especializados em Engenharia de Segurança e em Medicina do Trabalho:. Disponível em: http://trabalho.gov.br/images/Documentos/SST/NR/NR4.pdf. Acesso em: 12 set. 2017.

BRASIL(e). Ministério do Trabalho e Emprego. Norma Regulamentadora 5: Comissão Interna de Prevenção de Acidentes. Disponível em:

http://trabalho.gov.br/images/Documentos/SST/NR/NR5.pdf . Acesso em: 12 de set. 2017.

BRASIL(e). Ministério do Trabalho e Emprego. Norma Regulamentadora 7: Programa de Controle Médico de Saúde Ocupacional. Disponível em:

http://trabalho.gov.br/images/Documentos/SST/NR/NR7.pdf . Acesso em: 12 set. 2017.

BRASIL(d). Ministério do Trabalho e Emprego. Norma Regulamentadora 09: Programa de Prevenção de Riscos Ambientais-PPRA. Disponível em:

http://trabalho.gov.br/images/Documentos/SST/NR/NR09/NR-09-2016.pdf. Acesso em: 12 set. 2017.

BRASIL(e). Ministério do Trabalho e Emprego. Norma Regulamentadora 15: Atividades e Operações Insalubres. Disponível em:

http://trabalho.gov.br/images/Documentos/SST/NR/NR15/NR-15.pdf. Acesso em: 12 set. 2017.

CAMARGO, Wellington. Gestão da segurança do trabalho. 2016.

COSTA, E. Estratégia e dinâmica competitiva. São Paulo: Editora Saraiva, 2009.

DA INDÚSTRIA, SESI-Serviço Social. Sebrae. Dicas de prevenção de acidentes e doenças no trabalho-saúde e segurança no trabalho-micro e pequenas empresas. 2005.

DA SILVA, Viviania Freire et al. RISCOS OCUPACIONAIS E ACIDENTES DE TRABALHO NA ENFERMAGEM. Mostra Interdisciplinar do curso de Enfermagem, v. 2, n. 1, 2017.

FERNÁNDEZ-MUÑIZ, Beatriz; MONTES-PEON, Jose Manuel; VAZQUEZ-ORDAS, Camilo Jose. Safety management system: Development and validation of a multidimensional scale. Journal of Loss Prevention in the process Industries, 2007, 20.1: 52-68. https://doi.org/10.1016/i.jlp.2006.10.002

GONÇALVES, Edwar Abreu. Manual de segurança e saúde no trabalho. LTr, 2006.

IBGE. Instituto Brasileiro de Geografia e Estatística: Disponível em:

https://www.ibge.gov.br/estatisticas-novoportal/sociais/populacao/9103-estimativas-depopulacao.html?edicao=16985\&t=resultados. Acesso em: 02 nov. 2017.

LAGO, Siomara Cristina Broch. Aplicação prática de atividades de inspeção de segurança e elaboração de mapa de riscos. UFSM-CT-Programa de Pós-Graduação em Engenharia de Produção (1997).

LANZA, Alis Karla Cadó. Riscos ergonômicos nos ambientes de trabalho: estudo aplicado aos berçários de creches públicas. Dissertação (especialização em engenharia 
de segurança no trabalho). 2010. 51 f. Faculdade de Arquitetura, Engenharia e Tecnologia, Universidade Federal de Mato Grosso, Cuiabá, 2010.

MORAIS, Evelyn Nascimento; SOARES, Enedina; LAMAS, Alinny Rodrigues. Ferramenta para o gerenciamento preventivo dos riscos ocupacionais dos trabalhadores de enfermagem: mapa de riscos. Revista pesquisa cuidado é fundamental online, Rio de Janeiro, v. 2, n. 3, p. 1039-1047, julho/setembro, 2010.

MESQUITA, Luciana Sobreira de. Gestão da segurança e saúde no trabalho: um estudo de caso em uma empresa construtora. 1999. Dissertação (Mestrado em Engenharia de Produção), Universidade Federal da Paraíba, João Pessoa.

NOVELLO, R.; NUNES, R. S.; MARQUES, R. S. R. Análise de Processos e a Implantação do Mapa De Risco Ocupacional em Serviços De Saúde: Um Estudo no Serviço de Hemoterapia de uma Instituição Pública Federal. In: CONGRESSO NACIONAL DE EXCELÊNCIA EM GESTÃO, 7., 2011. Anais... Rio de Janeiro, 2011.

OLIVEIRA, C. L.; PIZA, F. T. Segurança e saúde no trabalho. São Caetano do Sul, Difusão, v. 2, 2016, 222 p. https://doi.org/10.1590/S0102-88392003000200002

OLIVEIRA, João Cândido de. Segurança e saúde no trabalho: uma questão mal compreendida. São Paulo em perspectiva, v. 17, n. 2, p. 03-12, 2003.

RODRIGUES. Celso Luiz Pereira. Introdução à engenharia de segurança do trabalho. 1995. Apostila (Curso de Especialização em Engenharia de Segurança), Universidade Federal da Paraíba, João Pessoa.

SAAD, Irene e GIAMPAOLI, Eduardo. Programa de prevenção de riscos ambientais PPRA NR- 9 COMENTADA. São Paulo: ABHO, 2005.

SANTOS, É. I.; VALOIS, B. R. G. Riscos ocupacionais relacionados ao trabalho de enfermagem: Revisão integrativa de literatura. Revista Augustus, v. 16, p. 78-87, 2011.

SANTOS, J. Introdução à engenharia de segurança. Mapa de risco. Santo André: FAENG, 2008.

SEBRAE, Bares e Restaurantes um setor em expansão. Disponível em: http://www.sebrae.com.br/sites/PortalSebrae/artigos/bares-e-restaurantes-um-setor-emexpansao,1038d53342603410VgnVCM100000b272010aRCRD. Acesso em: 13 out. 2017.

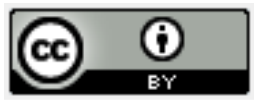

Artigo recebido em: 01/06/2018 e aceito para publicação em: 30/05/2019 DOI: http://dx.doi.org/10.14488/1676-1901.v19i2.3268 